Ferdous Sohel ORCID iD: 0000-0003-1557-4907

\title{
A Review of the Uses of Virtual Reality in Engineering Education
}

\author{
Jaiden Aaron di Lanzo \\ College of Science, Health, Engineering and Education \\ Murdoch University \\ Murdoch, WA 6150, Australia

\section{Andrew Valentine} \\ School of Information Technology and Electrical Engineering \\ The University of Queensland \\ Brisbane Qld 4072, Australia \\ Ferdous Sohel $^{1}$ \\ College of Science, Health, Engineering and Education \\ Murdoch University \\ Murdoch, WA 6150, Australia \\ Email: F.Sohel@murdoch.edu.au

\section{Angie Yean Tze Yapp} \\ College of Science, Health, Engineering and Education \\ Murdoch University \\ Murdoch, WA 6150, Australia

\section{Kudakwashe Chandafira Muparadzi} \\ College of Science, Health, Engineering and Education \\ Murdoch University \\ Murdoch, WA 6150, Australia \\ Merkorios Abdelmalek \\ College of Science, Health, Engineering and Education \\ Murdoch University \\ Murdoch, WA 6150, Australia
}

\begin{abstract}
${ }^{1}$ Corresponding author

90 South Street

Murdoch, WA 6150, Australia

Email: F.Sohel@murdoch.edu.au

Phone: +61 893602059
\end{abstract}

The use of virtual environments as pedagogical tools within the domain of education has become an increasingly popular phenomenon over the last few decades especially. However, the uses and effects of virtual environments as pedagogical tools within the specific domain of engineering education has not been explored in extensive detail.

This is the author manuscript accepted for publication and undergone full peer review but has not been through the copyediting, typesetting, pagination and proofreading process, which may lead to differences between this version and the Version of Record. Please cite this article as doi: 10.1002/cae.22243.

This article is protected by copyright. All rights reserved. 
The limited body of current research regarding the uses of virtual environments in engineering education affords a unique opportunity. This review provides an overview and synthesis of the uses of virtual reality within the domain of engineering education through the systematic analysis of journal articles and conference proceedings published across two databases (IEEE Xplore and Scopus) between 2015 and 2019. In summary, 17 studies were analysed utilising a systematic approach and using a coding scheme including four main categories and 12 binary items. The findings indicate an escalation in the use of virtual classroom environments as supplementary to traditional teaching environments, as well as reported substantial benefits to cognitive and skill-based learning outcomes. The findings suggest that evaluation metrics and processes which lack clarity, together with unrealistic virtual scenarios and small evaluation sample sizes, may confound comparison and hence the reported substantive and beneficial use of virtual reality environments in engineering education. Scholars and educators within the domain of engineering education should continue investigating the uses and merits of virtual reality environments as pedagogical tools, taking these issues into consideration.

\section{Keywords}

virtual reality; engineering education; systematic review; interactive software; immersive technology; educational technology

\section{Introduction}

In a 2017 review which examined 68 studies across primary, secondary, and tertiary education, Akçayır \& Akçayır $^{1}$ indicated that, within the context of educational settings, the use of virtual environments may potentially support teaching and learning. The review suggested that this pedagogical use for virtual environments may improve learner outcomes by promoting enhanced feelings of learning achievement and by enhancing learning performance. Furthermore, the review reported pedagogical contributions including enhanced enjoyment and improved levels of engagement, suggesting that the usefulness of virtual environments in educational settings is clear. ${ }^{1}$

Similarly, in a 2018 review which examined 21 studies, Jensen \& Konradsen ${ }^{2}$ indicated that the pedagogical application of virtual environments is useful in several situations. The review identified benefits to cognitive (remembering and understanding) skills, psychomotor (visual or observational) skills, and affective (emotional control) skills. However, it was suggested that the uses of virtual environments would have no added pedagogical value if the immersive experience distracts from the learning task. This pointed to a further need for rigorous research examining the promising beneficial uses of virtual environments in educational settings. $^{2}$

Within the past few decades, the use of virtual environments for pedagogical application in educational settings has become increasingly popular. Furthermore, the use of virtual environments has become increasingly popular within the specific

This article is protected by copyright. All rights reserved. 
context and domain of engineering education to assist in increasing motivation and to benefit the enrichment of learning experiences. ${ }^{1-4}$ Nonetheless, the tangible effects regarding the uses of virtual environments in engineering education have only recently begun to be explored. This is partly due to the limited body of current research in this domain and a disconnect between learners, educators, and industrial engineering practise regarding desired learning goals and competencies. ${ }^{5,6}$

The purpose of this review was to better understand the nature of the current uses of virtual environments in engineering education by gathering and synthesising selected literature across two scholarly databases. Through this synthesis, an improved understanding of the current situation regarding the uses of virtual environments within the domain of engineering education has been formulated. Furthermore, this review adds to the limited body of research in this domain and contributes to future considerations and directions regarding the uses of virtual environments as pedagogical tools within the context of engineering education.

\section{Background}

The uses of virtual environments in educational settings is becoming both a popular and widely employed phenomena, with studies showing that the use of virtual environments as pedagogical tools may offer many advantages to educational settings and aid in enriching the learning and teaching experience. ${ }^{1-3}$ Virtual environments may allow students to develop skills that are otherwise difficult to acquire using more traditional teaching and learning methods. ${ }^{4}$ Furthermore, virtual environments can assist in improving motivation, ${ }^{1,3}$ and may help to enhance learning and processing skills. ${ }^{7}$

There exists a substantial body of current and older research regarding the uses of virtual environments in the context of educational settings. Since the 1990's, the use of virtual environments within educational domains has been explored as a means with which to supplement traditional teaching and learning methods. A study published in 1996 implemented innovative electronic homework and quiz problems to be run on stand-alone computers for submission and grading using the internet. Furthermore, the study used asynchronous conferencing software to create a virtual classroom which afforded learners and teachers the opportunity to interact over computer networks from remote locations. ${ }^{8}$

A 2002 study investigating the uses of augmented reality within the domain of geography education attempted to find a solution to suggested student difficulties in accommodating spatially related knowledge involving complex geographical concepts and phenomena (specifically, Earth-Sun relationships). This study indicated that virtual environments may have the potential to transform instruction and learning of complex spatial concepts in geography education, suggesting that virtual environments provide efficient, powerful tools that allow students to view and interact with complex and sophisticated conceptual content while providing exploratory flexibility. ${ }^{9}$ The following year, a 2003 study presenting a fully functional educational augmented reality application for mathematics and geometry education reported that

This article is protected by copyright. All rights reserved. 
initial conceptual evaluations were encouraging, but that more work remains to be done regarding evaluation of the practical and pedagogical value for such an application. ${ }^{10}$ More recently, a 2013 study reported that, with appropriate pedagogical design, virtual environments may have the potential to help students learn more effectively. ${ }^{7}$ However, tangible research regarding the uses of virtual environments within the domain of engineering education has only recently been explored in any detail.

Notably, the use of virtual environments within the domain of medical education has been predominant, well documented, and oft reviewed over the past few decades. ${ }^{11-23}$ Numerous studies investigating the uses of virtual environments in medical education have been published, with several studies concluding that the application of virtual environments can be used to supplement conventional learning and improve performance. $^{15,18,21,23}$

A 2018 review concluded that early conventional endoscopy training for health profession trainees with limited to no prior endoscopic experience may be supplemented (though not replaced) by virtual reality simulation-based training. ${ }^{23}$ Similarly, a 2013 review, assessing the potential benefits and harms of the uses of virtual reality training for surgical trainees in laparoscopic surgery, concluded that supplementary virtual reality training decreased operating time and improved operative performance of surgical trainees with limited laparoscopic experience when compared with no or conventional, supervised, patient-based training. ${ }^{18}$ Additionally, a 2005 BEME systematic review (which spanned 34 years, from 1969 to 2003) focussing on the uses of high-fidelity simulation-based medical education concluded that such uses are educationally effective and complement traditional medical education, though conceded that improvement of the rigour and quality of research in the field was necessary. ${ }^{17}$

Conversely, a 2015 review into virtual reality simulation-based training for improving surgical skills of the ear, nose, or throat found limited evidence to support the beneficial uses of virtual reality simulation-based education to enhance conventional teaching, learning, and training methods. ${ }^{20}$

Furthermore, it has been found that these technologies may be difficult to use for both learners and teachers, which may contribute to cognitive overload in those using such technologies. ${ }^{1}$ Additionally, there may be an overall reluctance to the use of these technologies in educational settings as traditional methods of teaching and learning hold fast; educators and students unwilling to forego traditional theoretical and conceptual educational approaches in favour of more practical approaches. ${ }^{4}$

Motivated by the current and increasingly popular use of virtual environments in educational settings, this study presents a review of the literature regarding the substantive nature of the current status and effects of virtual reality environments within the context of engineering education.

This article is protected by copyright. All rights reserved. 


\section{Methodology}

This study utilised a systematic literature review approach to synthesise prior work, better inform practise, and identify important new directions for research to benefit the field of engineering education. This process defined a series of steps to consider when conducting a systematic literature review, which included: (a) deciding to do a systematic review; (b) identifying scope and research questions; (c) finding and cataloguing resources; (d) critiquing and appraising; and (e) synthesising. ${ }^{24}$ Additionally, these steps have been adapted elsewhere in the literature. ${ }^{25}$ This adaptation ${ }^{25}$ has been used to guide the review process in this investigation as follows:

1. Reviewing: Deciding to do a systematic literature review.

2. Defining: Identifying and defining primary and secondary research questions.

3. Scoping: Identifying and defining where and how to look for the literature.

4. Cataloguing: Gathering the literature and creating a database.

5. Exploring: Engaging with the gathered literature, developing a coding framework, and selecting relevant literature based on exclusion criteria.

6. Coding: Re-engaging with the literature and coding and re-coding each article based on the coding framework.

7. Quantizing: Evaluating descriptive statistics relative to the coding framework and comparing the findings.

8. Interpreting: Evaluating the qualitative meaning and identifying the implications of the findings in relation to the literature.

9. Narrating: Developing a written overview of the reviewed literature.

The process was not linear. For example, the coding process was revisited during the quantizing process to further generalise and condense identified codes and code items so that descriptive statistics could be more concisely reported, and findings more easily compared.

\section{Defining: Research Question and Secondary Questions}

This review focussed on the uses of virtual reality in teaching and learning environments within the context of engineering education. The objective was to assess the relevance of identified studies, identify common themes amongst studies, and holistically assess the literature to synthesise and discuss the findings. More specifically, the following research question guided this review:

RQ1: What are the ways in which virtual reality is currently being used within the context of engineering education?

Furthermore, the following secondary research questions were included:

RQ1.1. Who within the context of engineering education is using virtual reality?

RQ1.2. What kinds or types of virtual reality technologies are being used in engineering education?

RQ1.3. In what format is virtual reality being used in engineering education?

This article is protected by copyright. All rights reserved. 
RQ1.4. What are the most common motivations for using virtual reality in engineering education?

RQ1.5. What are the common reported learning outcomes of using virtual reality in engineering education?

RQ1.6. How are the uses of virtual reality in engineering education evaluated?

\section{Scoping: Where and How to Look for the Literature}

Literature was collected from two research databases. One database covers the field of engineering (IEEE Xplore), and the other is interdisciplinary (Scopus). One engineering-specific database was used to capture indexed records which are current and specifically contained within the domain of engineering. One interdisciplinary database was used to capture indexed records across a broader spectrum of disciplinary domains and publication venues.

This review includes peer-reviewed journal articles and conference proceedings which focus on the uses of virtual reality within the context of engineering education. Initially, test queries were conducted using the following initial Boolean search string:

virtual reality AND engineering education

To assist in acquiring and validating the final primary search string, test queries were conducted with a search string containing alternative terms to describe the term engineering education as follows:

\section{virtual reality AND engineering AND (education OR training OR learning OR teaching)}

Test queries conducted using this search string returned records which varied slightly from test queries conducted using the initial search string. However, it was concluded that the use of these alternative terms in the search string did not significantly accrue further substantially relevant results when compared to the initial search string. As such, the initial search string was used as the final primary search string.

Alternative scoping searches including the terms augmented reality and mixed reality in the search string were also conducted. It was concluded that the inclusion of such terms too widely broadened the scope of the review.

\section{Cataloguing: Gathering the Literature}

Both databases were queried using the following Boolean search string:

$$
\text { virtual reality AND engineering education }
$$

This search string queried overall record metadata, including keywords and titles. The search was limited to include only journal articles and conference proceedings. Since the focus of this review is on the current uses of virtual reality in engineering education, and due to recent trends in the adoption of and research for virtual reality in engineering education, the search was limited to include only those studies

This article is protected by copyright. All rights reserved. 
published since the 1st of January, 2015. The last search was conducted on the 2nd of May, 2019. Figure 1 (Appendix A) visualises the yearly publication trend for examined and included studies.

Overall, the search returned a total of 4,448 references to records across both databases. Record screening adopted a two-phase approach; first from within the database, and then from within a spreadsheet. From within each database, retrieved records were filtered to include: only journal articles and conference proceedings; only studies published since the 1st of January, 2015; only records which contained the index terms virtual reality and engineering education. The first phase of record screening yielded a total of 1,248 non-unique records across both databases.

During the second phase of record screening, the search results from both databases were exported to a spreadsheet of records. The records in the spreadsheet were filtered further to include only those records which contained the terms virtual reality and engineering in the study title. The second phase of record screening yielded a total of 40 non-unique records across both databases.

As such, the record inclusion criteria specified that a study:

1) must contain the key word or index terms virtual reality and engineering education;

2) must be published as a journal article or conference proceeding;

3) must be published on or after the 1st of January, 2015 and before or on the date of the last search (the 2nd of May, 2019);

4) must contain the terms virtual reality and engineering in the study title.

Since the search spanned more than one database (one of which is interdisciplinary) there were several duplicate records from across both databases. Duplicate records were removed ( $n=8)$, leaving 32 unique records for screening based on abstract. Figure 2 (Appendix A) presents a visual overview of this process.

\section{Exploring: Selecting the Literature}

At the beginning of this phase, each of the 32 unique records were independently evaluated and screened by two authors using study abstracts and guided by the inclusion and exclusion criteria (described below). When both authors agreed that a study satisfied all criteria, the study proceeded to and was included in the next phase of analysis. Disagreements in evaluation between authors were discussed and resolved (possibly resulting in the formulation of a new inclusion or exclusion criterion) to ensure a rigorous evaluation and screening process based on author consensus. When a new exclusion criterion was created, all studies were subsequently evaluated (or reevaluated) against the new criterion.

The large number of records identified in the initial search---in contrast with the small number of unique records identified through the screening process---may be telling of the ambiguity of the term virtual reality. This is reflected in the number of studies assessed which, despite satisfying the search inclusion criteria, discussed and focussed

This article is protected by copyright. All rights reserved. 
on virtual environments which do not strictly constitute virtual reality, such as augmented reality and mixed reality. As such, records focussing upon studies which depart from the strictly narrow scope of virtual reality were excluded. Furthermore, records focussing upon studies which discussed the uses of virtual reality not within the context of engineering education were also excluded. Additionally, records which are not accessible in the English language or for which the full-text manuscript is inaccessible were also excluded. As such, the four record exclusion criteria specified that a study:

1) full-text manuscript must be available;

2) full-text manuscript must be available in English;

3) must describe the use of only virtual reality;

4) must be contained within the context of some discipline of engineering education.

It was required that each record satisfy (i.e., not violate) each exclusion criterion for inclusion in the subsequent full-text appraisal. The process of screening the 32 unique records based on the abstracts identified 22 relevant records, with 10 records being excluded based on the specified exclusion criteria. The reasons for exclusion are presented in Figure 2 (Appendix A).

Appraisal of the 22 relevant records was conducted by examining the study full-text manuscripts. The full-text appraisal was guided by the four record exclusion criteria, with each document being required to satisfy each criterion in order to be considered for synthesis and inclusion in the review. During this phase, the full-text manuscript for each of the 22 relevant records was independently evaluated by two authors. Each author read through the full-text manuscript for each record and determined inclusion or exclusion based on the inclusion and exclusion criteria. Disagreements in evaluation between authors were discussed and resolved (possibly resulting in the formulation of a new inclusion or exclusion criterion) to ensure a rigorous evaluation process based on author consensus. When a new exclusion criterion was created, all studies were subsequently evaluated (or re-evaluated) against the new criterion.

From the 22 relevant records identified in record screening based on abstract, 17 were deemed appropriate for appraisal based on the study full-text manuscripts, with 5 records being excluded based on the specified exclusion criteria. The reasons for exclusion are presented in Figure 2 (Appendix A). The remaining 17 studies were therefore deemed applicable for inclusion in the review.

\section{Coding: Developing a Categorical Framework}

During the next phase, the authors began generating a coding framework. Each study was considered holistically in the context of each other study, with the purpose of identifying any common themes present throughout the gathered literature. As such, the coding framework was developed inductively. Inductive codes involved a generalisation of commonly identified themes in the literature.

This article is protected by copyright. All rights reserved. 
A part of the analysis included creating a general study overview (this information was not used to generate the coding framework). This included items such as the title of the study, the publication year of the study, the discipline(s) of the course listing(s) or for which the study is applicable, and the type of virtual reality technology (hardware or software) used to conduct the study. Figure 3 (Appendix A) presents a visualisation of key words for the primary body of literature.

Each manuscript was read and analysed by two of the authors. The role of each author was to analyse and summarise each study individually and inductively generalise common themes present amongst the literature. This process was iterative, and initially identified categories were further inductively refined to generate the coding framework. Once the coding framework was complete, each study was once again examined by two of the authors. The role of each author was to categorise each study based on the coding framework. Most of these items were subjective interpretations of the authors, such as where and how learning outcomes were categorised, and what the general and condensed motivations for a study were. As such, the validity of the coding process was largely dependent on the clarity and inductive codification of the author(s). Disagreements between the authors were discussed and resolved based on author consensus to ensure a rigorous summarisation, analysis, and categorisation of individual studies.

Upon completion, the coding framework included four categories with 12 binary items. Table 1 presents an overview of the main categorical codes and binary code items. Precise definitions of the codes and code items are provided in the following sections.

\section{Quantizing: Findings and Descriptive Statistics}

\section{Overview of Studies: Engineering Disciplines and Types of Virtual Reality}

In response to Research Question 1.1, "Who within the context of engineering education is using virtual reality?”, 11 studies explicitly specified some discipline(s) of engineering for which the uses of virtual reality were explored in educational environments. An equal number of these studies explored the uses of virtual reality in civil engineering ( $n=4 ; 24 \%)$ and mechanical engineering $(n=4 ; 24 \%)$ environments. A smaller number of studies explored the uses of virtual reality in electrical engineering $(n=2 ; 12 \%)$ and industrial engineering $(n=2 ; 12 \%)$ environments. Furthermore, the uses of virtual reality in pneumatics $(n=1 ; 6 \%)$ and software engineering ( $n=1 ; 6 \%)$ environments were explored in a limited number of studies.

Additionally, one study explored the uses of virtual reality in both electrical engineering and mechanical engineering environments. ${ }^{26}$ Another study explored the uses of virtual reality in environments for three disciplines of engineering; civil engineering, industrial engineering, and mechanical engineering. ${ }^{27}$

Several studies ( $n=6$; 35\%) did not explicitly specify any discipline of engineering for which the uses of virtual reality were explored in educational environments. Table

This article is protected by copyright. All rights reserved. 
2 provides a summary of engineering disciplines; Figure 4 (Appendix A) visualises this information. Note that some studies specified more than one engineering disicipline, and so the total number of studies $n$ does not add to 17 .

In response to Research Question 1.2, "What kinds or types of virtual reality technologies are being used in engineering education?”, 12 studies specified a type of virtual reality technology. Most studies reported using one type of virtual reality technology. Over one half of those studies explored the uses of head-mounted display (HMD) virtual reality within engineering education environments $(n=9 ; 53 \%)$. A smaller number of those studies investigated the uses of desktop virtual reality ( $n=$ $2 ; 12 \%)$ and mobile virtual reality ( $n=2 ; 12 \%)$ within engineering education environments. Only one study explored the uses of a Cave Automatic Virtual Environment (CAVE) virtual reality system within an engineering education environment.

Several studies also reported using more than one type of virtual reality technology. One study explored the uses of both a Cave Automatic Virtual Environment (CAVE) virtual reality system and of head-mounted display (HMD) virtual reality within engineering education environments. ${ }^{28}$ Another study explored the uses of both headmounted display (HMD) virtual reality and of mobile virtual reality within engineering education environments. ${ }^{29}$

Several studies ( $n=5 ; 29 \%$ ) did not explicitly specify the type of virtual reality technology used in the study. Table 3 provides a summary of the types of virtual reality technologies used throughout the studies; Figure 5 (Appendix A) visualises this information. Note that some studies specified more than one virtual reality technology and so the total number of studies $n$ does not add to 17 .

\section{Class Format}

This category addressed Research Question 1.3: "In what format is virtual reality being used in engineering education?”. In general, class delivery formats of virtual reality in educational settings may be divided into two distinct groupings: (a) Virtual; and (b) Traditional.

Most studies which specified a delivery format explored or investigated the uses of virtual reality in the virtual classroom format $(n=10 ; 59 \%)$, attempting to represent or replicate real-world engineering classroom environments in a three-dimensional virtual environment. A slightly smaller number of studies explored or investigated the uses of virtual reality in the traditional classroom format ( $n=6$; 35\%), using virtual reality to complement traditional, lecture-based learning.

Additionally, a small minority of studies compared the uses of virtual reality in both the virtual and traditional classroom format $(n=2 ; 12 \%)$. Table 4 presents this information.

This article is protected by copyright. All rights reserved. 
A small number of studies ${ }^{30-32}$ did not explicitly specify any kind of delivery format for which the uses of virtual reality in engineering education were explored or investigated $(n=3 ; 18 \%)$.

\section{Rationale \& Justification}

This category addressed Research Question 1.4: "What are the most common motivations for using virtual reality in engineering education?”. Each of the 17 studies identified and specified a justification for which a use of virtual reality in engineering education should be explored, investigated, or developed. Three main general items are oft present amongst the reviewed literature: (a) Distance Learning; (b) Immersive Learning; and (c) Recent Development \& Integration.

Most studies pointed to recent development in and integration of virtual reality technologies in educational environments as a main motivating factor for exploring, investigating, or developing uses of virtual reality in engineering education ( $n=10$; 59\%). Following closely, many studies referenced the expected educational benefits of immersive learning environments as a main motivating factor for exploring, investigating, developing, or using virtual reality in engineering education $(n=9$; $53 \%$ ). A smaller number of studies pointed to the benefits of distant or remote learning methods, where virtual reality is used as a tool to provide distant or remote students with learning experiences they might not otherwise have, as a main motivating factor $(n=3 ; 18 \%)$.

Additionally, several studies ( $n=5 ; 29 \%$ ) specified more than one main motivating factor. ${ }^{29,32-35}$ A pair of studies pointed to the benefits of both distance learning methods and immersive learning environments as the main motivating factors. ${ }^{34,35} \mathrm{~A}$ triad of studies referenced the benefits of immersive learning environments as well as recent development in and integration of virtual reality technologies as the main motivating factors. ${ }^{29,32,33}$ Table 5 presents an overview of the rationale and justification that studies specified for using virtual reality in engineering education.

\section{Learning Outcomes}

This category addressed Research Question 1.5: "What are the common reported learning outcomes of using virtual reality in engineering education?”. The binary items developed for this category included items inductively extracted from the studies and generalised in consideration of a commonly cited source ${ }^{36}$. The items encompass three broad and main categories: (a) Skill-based Outcomes; (b) Cognitive Outcomes; and (c) Affective Outcomes. Descriptions of the items are as follows:

1. Skill-based Outcomes. This learning outcome focuses on the evaluation of performance in simulated and training environments and concerns the development of technical or motor skills. This is presented as an enhancement or improvement of students' academic graded performance.

2. Cognitive Outcomes. This learning outcome focuses on the evaluation of the dynamic processes of knowledge acquisition, organisation, and application.

This article is protected by copyright. All rights reserved. 
This is presented as an enhancement or improvement of students' knowledge retention and overall understanding.

3. Affective Outcomes. This learning outcome focuses on the evaluation of issues such as attitudes, motivations, and goals that are relevant to specified engineering learning goals. This is presented as an enhancement, improvement, or facilitation of students' development or acquisition of professional and personal skills ('soft' skills).

Most studies specified learning outcomes which aimed to improve or enhance students' longer-term knowledge retention and understanding of specified academic concepts and formations via the use of virtual reality in educational engineering environments ( $n=6$; 35\%). A similar number of studies specified learning outcomes which aimed to improve or enhance students' traditionally graded academic scorings of academically examinable content via the use of virtual reality in educational engineering environments $(n=5 ; 29 \%)$. Just under one quarter of studies specified learning outcomes which aimed to improve or facilitate students' acquisition and development of affective industry and professional skills via the use of virtual reality in educational engineering environments $(n=4 ; 24 \%)$.

One study specified more than one learning outcome. ${ }^{30}$ This study specified learning outcomes which aimed to improve or enhance students' knowledge retention and overall understanding as well as to improve or facilitate students' affective industry and professional skills acquisition and development.

Just under one fifth of studies ${ }^{32,34,37}$ did not clearly specify any particular learning outcomes ( $n=3 ; 18 \%$ ). Table 6 provides an outline of the reported benefits to learning outcomes by using virtual reality in engineering education.

\section{Evaluation Metrics}

This category addressed Research Question 1.6: "How are the uses of virtual reality in engineering education evaluated?". In general, studies identified a metric for evaluation whereby a developed virtual reality solution was evaluated. Evaluations often took the form of post-use surveys provided to experiment participants.

Generally, the average scorings specified by study participants for specific survey items were used to aggregate or reflect the average scorings for evaluation metrics specified by the study. A generalisation of common evaluation metrics presents three main binary items: (a) Acceptability \& Validity; (b) Usability \& Usefulness; and (c) Utility \& Effectiveness.

Most studies assessed and discussed metrics used to evaluate the utility and overall perceived effectiveness of the use of a virtual reality system in engineering education environments ( $n=8 ; 47 \%)$. Just over one third of studies assessed and discussed metrics used to evaluate the usability and overall perceived usefulness of the use of a virtual reality system in engineering education environments $(n=6 ; 35 \%)$. A small number of studies assessed and discussed metrics used to evaluate the acceptability

This article is protected by copyright. All rights reserved. 
and overall perceived validity of the use of a virtual reality system in engineering education $(n=2 ; 12 \%)$.

Some studies specified more than one evaluation metric by which a virtual reality solution was evaluated: a singular study assessed and discussed metrics used to evaluate both the acceptability and usability of a virtual reality system ${ }^{37}$; another singular study assessed and discussed metrics used to evaluate all of the acceptability, usability, and utility of a virtual reality system ${ }^{38}$.

Just under one quarter of studies ${ }^{31,32,34,39}$ did not specify any particular evaluation metrics, or otherwise did not perform or report on any formal evaluation of a virtual reality system in an engineering education environment $(n=4 ; 24 \%)$. Table 7 provides an overview of the metrics used in evaluating virtual reality systems.

\section{Interpreting \& Narrating: Discussion}

\section{Virtual Classrooms}

Studies examining the uses of three-dimensional virtual classroom environments within this review have demonstrated that such environments were helpful in creating safe, controlled situations by which complex and expensive industrial processes could be taught, visualised, and experimented with, as well as presenting situations which were otherwise inaccessible. However, issues often arise regarding excessive computer processing power and the lack of immersion due to unrealistic representations of real-world situations.

Virtual classroom environments were found to be effective in improving student retention and provide students with an enjoyable learning experience when compared to traditional classroom environments. ${ }^{27,40}$ Additionally, early tertiary learners were reported to be able to directly visualise and better understand certain engineering concepts. ${ }^{27,40}$ However, one study reported that, given the results of the study, the uses of virtual classroom environments is not cost-effective, and that further development in this area is necessary. ${ }^{40}$ Conversely, another study reported a cost-effective virtual reality solution given the results of user evaluation assessments. ${ }^{37}$

While virtual classroom environments have generally demonstrated a mitigation in the costs and risks associated with traditional, hands-on learning, it was also stated that the intent of virtual classroom environments is not necessarily to completely replace traditional classroom settings despite the reported benefits. ${ }^{41,42}$ Furthermore, virtual reality platforms may not be able to completely replace the human teacher-student interactions which occur in traditional classroom settings.

In mechanical and electrical engineering disciplines, virtual classroom environments can effectively assist students in retaining materials presented by instructors and improve their educational outcomes. For example, the participants in one study revealed that their understanding and memorisation process was improved while in a virtual reality environment. ${ }^{26}$ However, yet another study suggested that students exhibit the same level of retention in two-dimensional and three-dimensional

This article is protected by copyright. All rights reserved. 
environments, and it was suggested that learning in a virtual classroom environment does not impact retention. ${ }^{30}$

In several instances it was reported that the virtual environment did not feel realistic, which impacted immersion and thereby the overall learning experience. ${ }^{26,34,37}$ No study specifies the use of accurate three-dimensional scanning to recreate real-world situations in a virtual environment. Issues such as these present good opportunities for directing future research and development.

It is clear from the reviewed literature, however, that a general trend implies the beneficial use of virtual classroom environments in engineering education. Only a handful of studies presented results which demonstrated inconsequential or otherwise non-beneficial implications regarding the use of virtual classroom environments, though important points are raised regarding the cost-effectiveness and overall immersion due to simulated realism of current virtual classroom solutions.

Considering this, there should be a focus on the development of virtual classroom environments which accurately and realistically represent the chosen simulated environment to enhance and supplement current learning methods and environments. Furthermore, three-dimensional modelling methods should be more rigorously reported. Additionally, this should be balanced with the development and acquisition of solutions which are cost-effective for educational institutions.

\section{Learning Benefits}

In general, the included studies showed that the uses of virtual reality in engineering education may lead to promising and beneficial results in regards to desired learning outcomes for both tertiary and industry institutions, especially for skill-based and cognitive learning outcomes. ${ }^{27,31,39,40}$ While the widespread and standard use of virtual reality is yet to reach a point of feasible implementation within engineering education, it is stated that this is soon to be reversed as the cost of required technologies declines rapidly. ${ }^{40}$ One study mentions an active educational programme which provides several virtual reality learning activities to local schools, affording pre-university students the experience of real-world engineering simulations and scenarios. ${ }^{39}$ It is evident that current learning methods supplemented via the use of virtual reality learning tools can provide increasingly meaningful and effective experiences for both learners and educators. ${ }^{42}$

In one reviewed study, the results suggested that head-mounted display (HMD) virtual reality produced the most favourable results compared to the other common virtual reality systems due to higher immersion ratings typical of this technology. ${ }^{28}$ It is stated that a user immersed further into a virtual environment will exhibit quicker responses to interactions within that environment. ${ }^{30}$ However, drawbacks and issues associated with the use of head-mounted display (HMD) virtual reality devices include cases of cyber-sickness, motion sickness, disorientation, nausea, pallor, sweating, and headaches. ${ }^{32}$ Such issues may diminish the viability of virtual reality as a widespread tool for enhancing and developing specified skill-based learning outcomes in engineering education, presenting an opportunity for research focus in

This article is protected by copyright. All rights reserved. 
the future. Only one study evaluated the effects of cyber-sickness on study participants. $^{38}$

Furthermore, another study discovered that students who learned concepts within a virtual reality environment performed better than students who had learned concepts via traditional teaching methods, evident as an increase in reported student understanding of concepts, satisfaction, and a decrease in reported errors and completion time. ${ }^{43}$ The results of this study implied that advanced concepts are more digestible for students learning in a virtual reality environment and that they are more likely to be better prepared for the challenges of a real-world industrial workplace environment.

However, in some instances, experiment sample sizes were small and formal evaluation was not carried out, and so the reliability of conclusions resulting from such experiments may be unclear. ${ }^{34,37}$ Furthermore, some studies fail to discover or do not report the cost-effectiveness of proposed virtual reality systems and solutions, which could have implications in potential acceptability of such methods. ${ }^{38}$ As such, it is important to ensure that experiment sample sizes are adequately large and that rigorous evaluation of the benefits of virtual reality systems in engineering education contexts are performed so that statistically valid results may be presented and concluding outcomes may be more positively reinforced.

\section{Evaluation Considerations}

Often, the evaluation of the user experience within a virtual reality environment was assessed and evaluated without the use of a robust evaluation model. Questionnaires, usually using a Likert scale, were often been developed by researchers specifically for the study or experiment. While this approach is adequate in elucidating immediate and translatable feedback from study participants within the context of the study itself, the approaches are largely variable. This variation across the literature causes problems for and difficulty in the true assessment of the benefits of virtual reality when used within the context of engineering education.

In some cases, feedback systems have been developed and incorporated into virtual reality systems for study experimentation to better understand and evaluate purported benefits. ${ }^{27,40}$ Some studies found that student feedback is beneficial to the understanding and comprehension of student content retention and satisfaction with virtual reality applications. ${ }^{27,31,40}$

However, only a singular instance of a study made use of and explicit reference to a proposed model describing and providing several statistically validated metrics for evaluation. ${ }^{38,44}$ In some cases, it is confusing as to how or in what way a study is using various or minor sub-metrics to form an aggregate evaluation of an overall evaluation metric; in one instance, the level of acceptability for a virtual reality system is aggregated based on the maintainability, reliability, cost, safety, efficiency, and usability scorings gathered from study participants, though the specific criteria for acceptability is unclearly defined. ${ }^{37}$ The ad hoc nature of criterion definitions for

This article is protected by copyright. All rights reserved. 
evaluation metrics---aggregated or otherwise---creates a difficulty in comparison across the literature.

Taking this into consideration, a standardisation and clear defining of the criteria outlining major evaluation metrics in the context of virtual reality uses in engineering education---and a standardisation of the evaluation process itself---would prove useful for future evaluations of virtual reality uses in engineering education environments. In this way, individual and aggregated evaluation scorings may holistically elucidate the results of future studies and allow for an ease in comparison of such results across a broad body of literature.

\section{Future Research}

To further solidify the apparent conclusions drawn regarding the benefits of the uses of virtual reality in engineering education, questions regarding how to use virtual reality in engineering education, what users want from virtual reality in educational engineering courses, and which best-practise is applicable to the uses of virtual reality in the context of engineering should be asked.

To standardise user evaluation metrics and processes, and further elucidate general outcomes from findings related to the uses of virtual reality in engineering education, future research should focus on employing or developing robust and valid evaluation models as well as investigating easily and immediately comparable evaluation metrics. This can help to shift the results of virtual reality system and user evaluations from being confined to per-study bases towards a more general, comparable and standardised approach. This in turn can allow for easier comparisons to other relevant studies in the field.

Furthermore, emphasis should be placed on the realism of three-dimensional virtual reality scenarios. Such emphasis would help to improve the immersion users experience in a virtual reality learning environment. If applicable, three-dimensional scanning of real-world objects and situations should be used to represent objects in virtual reality environments. However, hardware and software limitations could prevent this.

\section{Conclusion}

This study presented the results of a systematic review regarding the uses of virtual reality technology within the domain of engineering education. Consequently, this review indicated a limited body of current research regarding the uses of virtual environments within the domain of engineering education. Recently, the uses of virtual reality within the domain of engineering education have been mainly motivated by the current development and viability of virtual reality technologies. Additionally, the popularisation of virtual reality as a pedagogical tool used to represent complex real-world situations which allow correction and failure in safe and controlled environments has guided the breadth of current research.

This article is protected by copyright. All rights reserved. 
The use of virtual reality as teaching and learning tools supplementary to traditional engineering education methods presents positive results and beneficial effects for cognitive, skill-based, and affective learning outcomes. However, there exists a lack of standardisation and clarity of evaluation processes and metrics. Furthermore, absence of formal evaluation for proposed virtual reality tools and reported small evaluation participant populations may be detrimental in elucidating the true perceived benefits of the uses of virtual reality within the domain of engineering education. Additionally, the lack of realism oft suggested by study participants regarding three-dimensional virtual environments may distract students from specified learning tasks, negatively impacting the immersive learning experience.

In consideration of these issues, researchers and educators hoping to evaluate the use or make use of virtual reality environments in the context of engineering education should place emphasis on several aspects for future work. First, major evaluation metrics and evaluation processes should be defined with unequivocal clarity. Second, formal and rigorous evaluation should be conducted so that statistically sound results regarding the effects on learning outcomes (and potential learning benefits) may be reported. Third, the realism of three-dimensional virtual reality environments should be considered so as not to distract from learning goals. Lastly, scholars and educators should consider using virtual reality environments to strike a balance between cognitive, skill-based, and affective learning outcomes within the domain of engineering education so that engineering students may benefit from an enriched, well-rounded learning experience.

\section{Limitations}

The narrowly focussed range of studies included in this review, all of which came from some discipline of engineering education, usually offered very positive conclusions as regards the uses of virtual reality when applied to engineering education. However, although many positive findings have been reported, the flexible nature of the term virtual reality and the indefinite approaches taken in development and evaluation of virtual reality systems and solutions means that it is difficult to draw robust and general conclusions about the benefits of such systems and solutions in the context of engineering education. Additionally, the small experimental sample sizes reported in several studies mean that the reported benefits of relevant virtual reality solutions for engineering education must be observed tentatively.

Furthermore, virtual reality-based learning for engineering education is often compared to the learning presented in traditional classroom environments; some studies argue that this comparison approach is not valid or is logically impossible because valid comparison groups do not exist in these situations. ${ }^{45}$ However, this situation may have changed in recent years with the advent of computer-based teaching and learning, as well as the insurgence of virtual reality applications. As such, research of this type should be conducted to inform practise in engineering education.

This article is protected by copyright. All rights reserved. 


\section{References}

1. Akçayır M, Akçayır G. Advantages and challenges associated with augmented reality for education: A systematic review of the literature. Educational Research Review. 2017;20:1-11.

2. Jensen L, Konradsen F. A review of the use of virtual reality head-mounted displays in education and training. Education and Information Technologies. 2018;23(4):1515-1529.

3. Garzón J, Pavón J, Baldiris S. Systematic review and meta-analysis of augmented reality in educational settings. Virtual Reality. 2019(4):447-459.

4. Karabulut-Ilgu A, Jaramillo Cherrez N, Jahren CT. A systematic review of research on the flipped learning method in engineering education. British Journal of Educational Technology. 2018;49(3):398-411.

5. Male S. Generic Engineering Competencies: A Review and Modelling Approach. Education Research and Perspectives. 2010;37(1):25-51.

6. Male S, King R. Improving Industry Engagement in Engineering Degrees. Paper presented at: Proceedings of the 25th Annual Conference of the Australasian Association for Engineering Education (AAEE); 8-10 December, 2014; Palmerston North, New Zealand.

7. Wang T, Towey D. A Mobile Virtual Environment game approach for improving student learning performance in integrated science classes in Hong Kong International Schools. Paper presented at: Proceedings of 2013 IEEE International Conference on Teaching, Assessment and Learning for Engineering (TALE); 26-29 August, 2013.

8. Oakley B. A virtual classroom approach to teaching circuit analysis. IEEE Transactions on Education. 1996;39(3):287-296.

9. Shelton BE, Hedley NR. Using augmented reality for teaching Earth-Sun relationships to undergraduate geography students. Paper presented at: The First IEEE International Workshop Agumented Reality Toolkit; 29-29 September, 2002.

10. Kaufmann H, Schmalstieg D. Mathematics and geometry education with collaborative augmented reality. Comput Graph-UK. 2003;27(3):339-345.

11. Basdogan C, De S, Kim J, Manivannan M, Kim H, Srinivasan MA. Haptics in minimally invasive surgical simulation and training. IEEE Computer Graphics and Applications. 2004;24(2):56-64.

12. Basdogan C, Sedef M, Harders M, Wesarg S. VR-Based Simulators for Training in Minimally Invasive Surgery. IEEE Computer Graphics and Applications. 2007;27(2):54-66.

This article is protected by copyright. All rights reserved. 
13. Dalgarno B, Lee MJW. What are the learning affordances of 3-D virtual environments? British Journal of Educational Technology. 2010;41(1):10-32.

14. Dockx K, Bekkers EMJ, Van den Bergh V, et al. Virtual reality for rehabilitation in Parkinson's disease. Cochrane Database of Systematic Reviews. 2016(12).

15. Gallagher AG, Ritter EM, Champion H, et al. Virtual reality simulation for the operating room - Proficiency-based training as a paradigm shift in surgical skills training. Ann Surg. 2005;241(2):364-372.

16. Gurusamy K, Aggarwal R, Palanivelu L, Davidson BR. Systematic review of randomized controlled trials on the effectiveness of virtual reality training for laparoscopic surgery. Br J Surg. 2008;95(9):1088-1097.

17. Issenberg SB, McGaghie WC, Petrusa ER, Gordon DL, Scalese RJ. Features and uses of high-fidelity medical simulations that lead to effective learning: a BEME systematic review. Med Teach. 2005;27(1):10-28.

18. Nagendran M, Gurusamy KS, Aggarwal R, Loizidou M, Davidson BR. Virtual reality training for surgical trainees in laparoscopic surgery. Cochrane Database of Systematic Reviews. 2013(8):1-38.

19. Nedic Z, Machotka J, Nafalski A. Remote laboratories versus virtual and real laboratories. Paper presented at: 33rd Annual Frontiers in Education, 2003. FIE 2003.; 5-8 November, 2003; Westminster, CO, USA.

20. Piromchai P, Avery A, Laopaiboon M, Kennedy G, O'Leary S. Virtual reality training for improving the skills needed for performing surgery of the ear, nose or throat. Cochrane Database of Systematic Reviews. 2015(9):1-44.

21. Reznick RK, MacRae H. Medical education - Teaching surgical skills Changes in the wind. N Engl J Med. 2006;355(25):2664-2669.

22. Rosen J, Hannaford B, Richards CG, Sinanan MN. Markov modeling of minimally invasive surgery based on tool/tissue interaction and force/torque signatures for evaluating surgical skills. IEEE Transactions on Biomedical Engineering. 2001;48(5):579-591.

23. Khan R, Plahouras J, Johnston BC, Scaffidi MA, Grover SC, Walsh CM. Virtual reality simulation training for health professions trainees in gastrointestinal endoscopy. Cochrane Database of Systematic Reviews. 2018(8):1-118.

24. Borrego M, Foster MJ, Froyd JE. Systematic Literature Reviews in Engineering Education and Other Developing Interdisciplinary Fields. Journal of Engineering Education. 2014;103(1):45-76.

This article is protected by copyright. All rights reserved. 
25. Hess JL, Fore G. A Systematic Literature Review of US Engineering Ethics Interventions. Science and Engineering Ethics. 2018;24(2):551-583.

26. Kamińska D, Sapiński T, Aitken N, Rocca AD, Barańska M, Wietsma R. Virtual reality as a new trend in mechanical and electrical engineering education. Open Phys. 2017;15(1):936-941.

27. Laseinde OT, Adejuyigbe SB, Mpofu K, Campbell HM. Educating tomorrows engineers: Reinforcing engineering concepts through Virtual Reality (VR) teaching aid. Paper presented at: 2015 IEEE International Conference on Industrial Engineering and Engineering Management (IEEM); 6-9 December, 2015; Singapore, Singapore.

28. Alhalabi WS. Virtual reality systems enhance students' achievements in engineering education. Behav Inf Technol. 2016;35(11):919-925.

29. Akbulut A, Catal C, Yildı B. On the effectiveness of virtual reality in the education of software engineering. Comput Appl Eng Educ. 2018;26(4):918927.

30. Huang W. Evaluating the Effectiveness of Head-Mounted Display Virtual Reality (HMD VR) Environment on Students' Learning for a Virtual Collaborative Engineering Assembly Task. Paper presented at: 25th IEEE Conference on Virtual Reality and 3D User Interfaces, VR 2018; 18-22 March, 2018; Reutlingen, Germany.

31. Nelson ME, Ahn B. Virtual Reality Activities for Teaching Engineering Students Professional Development Skills. Paper presented at: 2018 IEEE Frontiers in Education Conference (FIE); 3-6 October, 2018; San Jose, CA, USA.

32. Stuchlíková L, Kósa A, Benko P, Juhász P. Virtual reality vs. reality in engineering education. Paper presented at: 2017 15th International Conference on Emerging eLearning Technologies and Applications (ICETA); 26-27 October, 2017; Starý Smokovec, Slovakia.

33. Dinis FM, Guimarães AS, Carvalho BR, Martins JPP. Development of virtual reality game-based interfaces for civil engineering education. Paper presented at: 2017 IEEE Global Engineering Education Conference (EDUCON); 25-28 April, 2017; Athens, Greece.

34. Dinis FM, Martins JP, Carvalho BR, Guimarães AS. Disseminating Civil Engineering through virtual reality: An immersive interface. Int J Online Eng. 2018;14(5):225-232.

35. Syed ZA, Wang T, Frady KK, et al. Use of virtual reality tools in an undergraduate mechanical engineering manufacturing course. Paper presented

This article is protected by copyright. All rights reserved. 
at: 124th ASEE Annual Conference and Exposition; 25-28 June, 2017; Columbus, United States.

36. Kraiger K, Ford JK, Salas E. Application of Cognitive, Skill-Based, and Affective Theories of Learning Outcomes to New Methods of Training Evaluation. Journal of Applied Psychology. 1993;78:311-328.

37. Cruz DRd, Mendoza DMM. Design and Development of Virtual Laboratory: A Solution to the Problem of Laboratory Setup and Management of Pneumatic Courses in Bulacan State University College of Engineering. Paper presented at: 2018 IEEE Games, Entertainment, Media Conference (GEM); 15-17 August, 2018; Galway, Ireland.

38. Muller N, Panzoli D, Galaup M, Lagarrigue P, Jessel J. Learning mechanical engineering in a virtual workshop: A preliminary study on utilisability, utility and acceptability. Paper presented at: 2017 9th International Conference on Virtual Worlds and Games for Serious Applications (VS-Games); 6-8 September, 2017; Athens, Greece.

39. Dinis FM, Guimarães AS, Carvalho BR, Martins JPP. An immersive Virtual Reality interface for Civil Engineering dissemination amongst pre-university students. Paper presented at: 2017 4th Experiment@International Conference (exp.at'17); 6-8 June, 2017; Faro, Portugal.

40. Tanner E, Savadatti S, Manning B, Johnsen K. Usability and cognitive benefits of a mobile tracked display in virtual laboratories for engineering education. Paper presented at: 2016 IEEE Symposium on 3D User Interfaces (3DUI); 19-20 March, 2016; Greenville, SC, USA.

41. Valdez MT, Ferreira CM, Martins MJM, Barbosa FPM. 3D virtual reality experiments to promote electrical engineering education. Paper presented at: 2015 International Conference on Information Technology Based Higher Education and Training (ITHET); 11-13 June, 2015; Lisbon, Portugal.

42. Makarova I, Khabibullin R, Belyaev E, Bogateeva A. The application of virtual reality technologies in engineering education for the automotive industry. Paper presented at: 2015 International Conference on Interactive Collaborative Learning (ICL); 20-24 September, 2015; Florence, Italy.

43. Salah B, Abidi MH, Mian SH, Krid M, Alkhalefah H, Abdo A. Virtual realitybased engineering education to enhance manufacturing sustainability in industry 4.0. Sustainability. 2019;11(5):1477.

44. Shin D-H, Biocca F, Choo H. Exploring the user experience of threedimensional virtual learning environments. Behaviour \& Information Technology. 2013;32(2):203-214.

This article is protected by copyright. All rights reserved. 
45. A Cook D. The Research We Still Are Not Doing: An Agenda for the Study of Computer-Based Learning. Academic medicine: journal of the Association of American Medical Colleges. 2005;80:541-548.

\section{Appendix A}

Figure 1 Publication trend per year for examined (pre-selection) and included (post-selection) studies between 2015 and 2019.

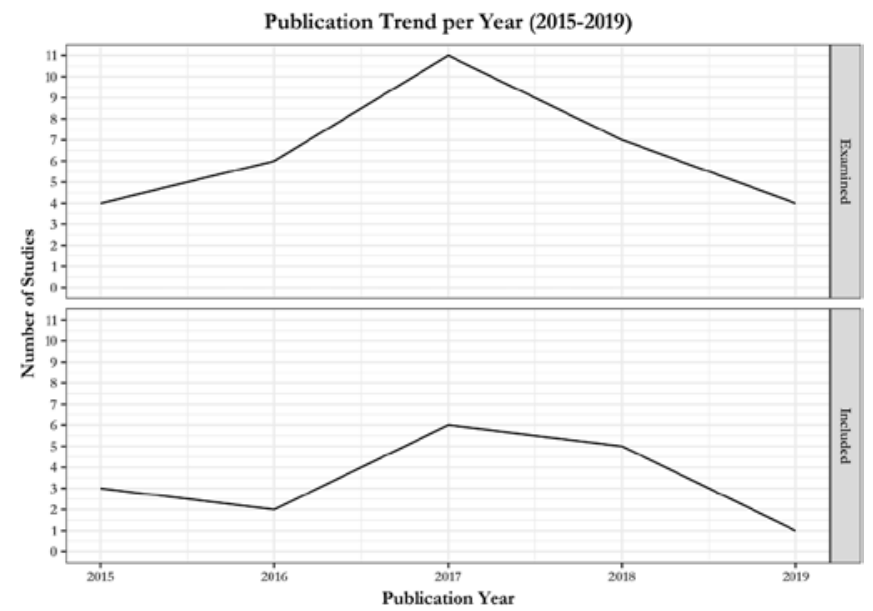

Figure $2 \quad$ Searching and selection process.

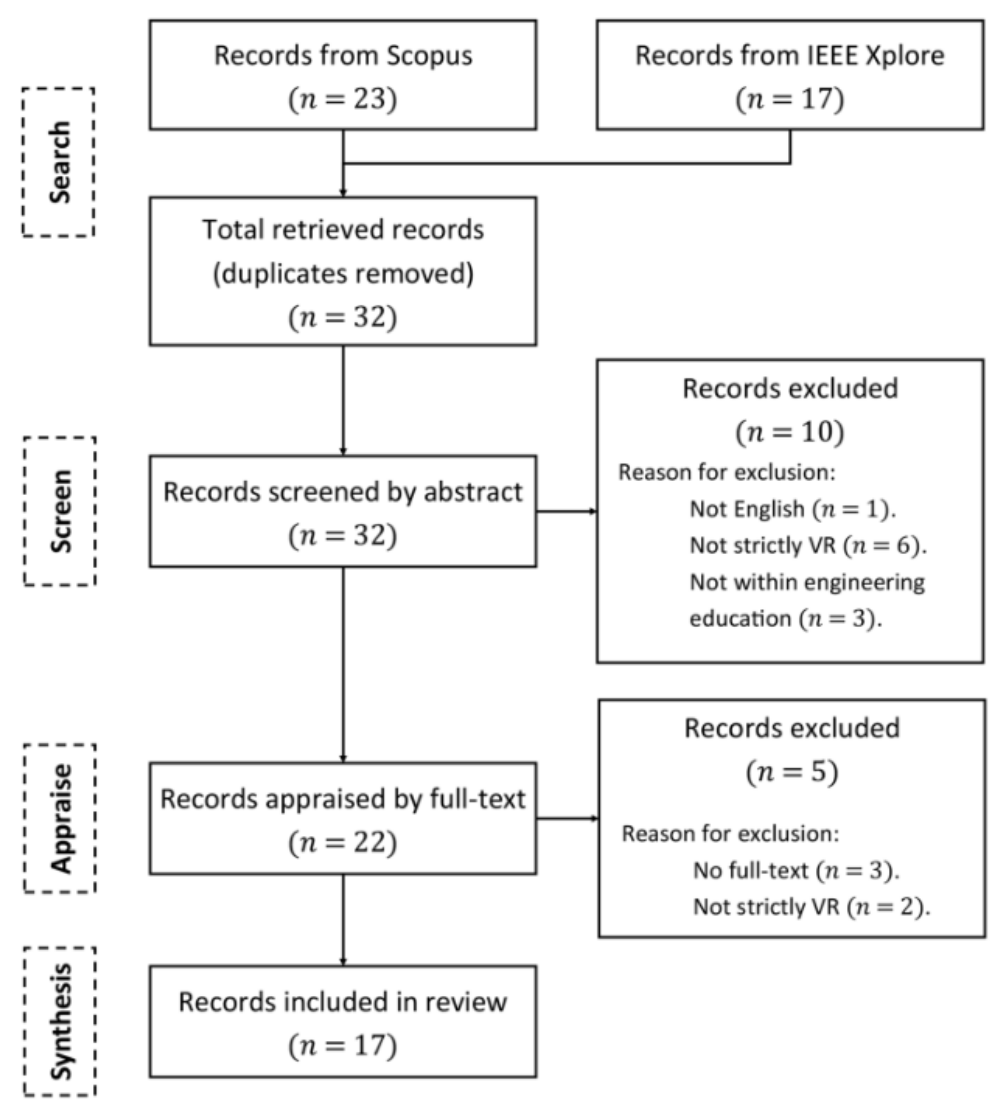

This article is protected by copyright. All rights reserved. 
Figure $3 \quad$ Word map of key words for primary studies.

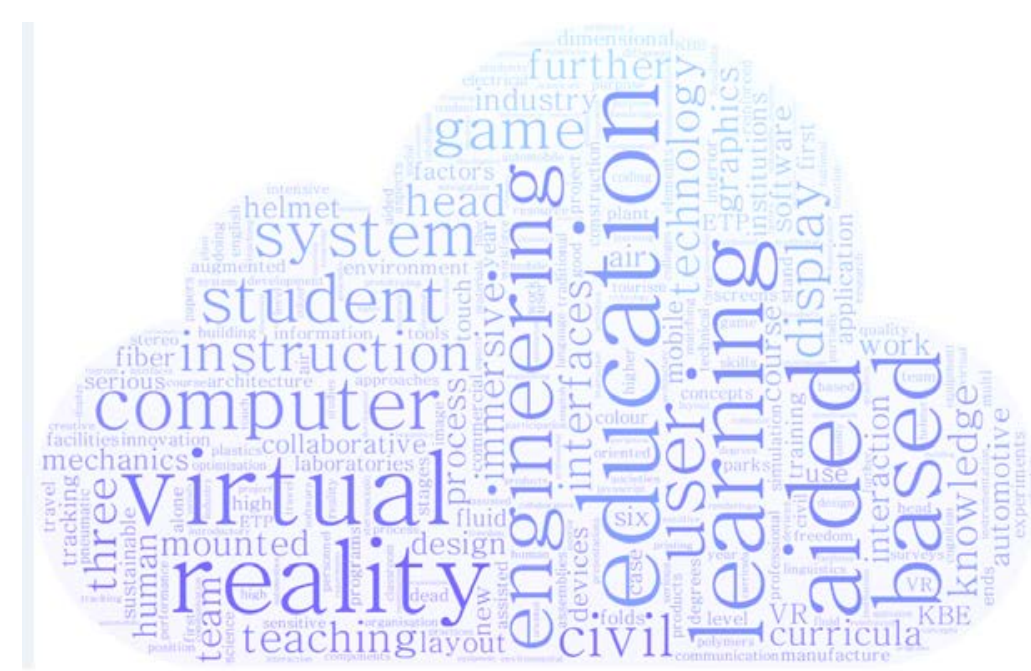

Figure $4 \quad$ Number of primary studies by different research facets (i.e., engineering disciplines).

Frequencies of Studies by Research Facets

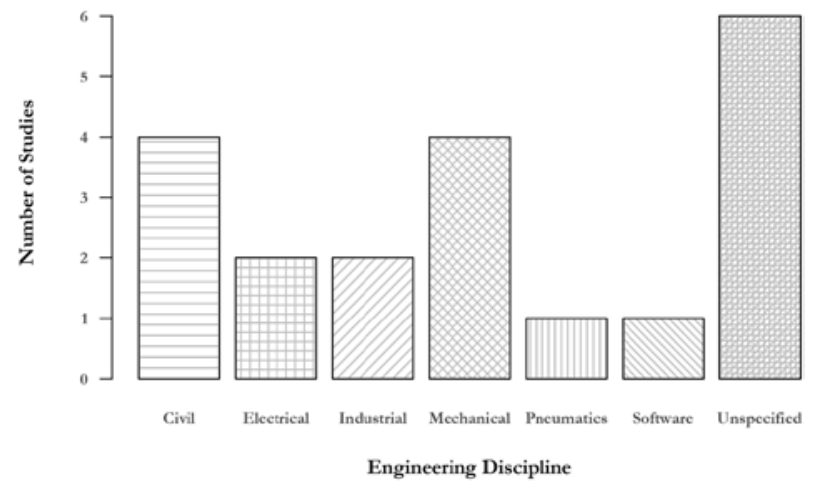

Figure $5 \quad$ Percentage of primary studies by different virtual reality technologies used.

Percentage of Studies by VR Technology Used

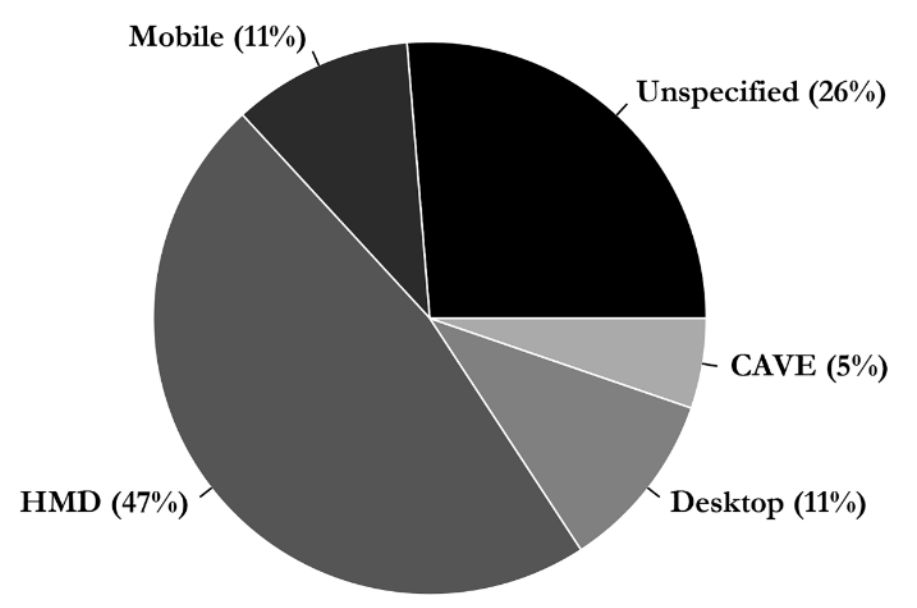

This article is protected by copyright. All rights reserved. 
Table 1 Overview of the coding framework.

\begin{tabular}{|l|l|}
\hline Category & Item \\
\hline 1. Class Format & Virtual \\
\hline & Traditional \\
\hline 2. Rationale \& Justification & Distance Learning \\
\hline & Immersive Learning \\
\hline 3. Learning Outcomes & Recent Development \& Integration \\
\hline & Academic Performance \\
\hline 4. Evaluation Metrics & Retention \& Understanding \\
\hline & Professional Skills Development \\
\hline & Acceptability \& Validity \\
\hline & Usability \& Usefulness \& Effectiveness \\
\hline & \\
\hline & \\
\hline & \\
\hline
\end{tabular}

Table 2 Overview of engineering disciplines and associated studies. Note that some studies specified more than one engineering discipline.

\begin{tabular}{|l|l|l|}
\hline Discipline Area & $n$ & Studies \\
\hline Civil & 4 & $27,33,34,39$ \\
\hline Electrical & 2 & 26,41 \\
\hline Industrial & 2 & 27,43 \\
\hline Mechanical & 4 & $26,27,35,38$ \\
\hline
\end{tabular}

This article is protected by copyright. All rights reserved. 


\begin{tabular}{|l|l|l|}
\hline Pneumatics & 1 & 37 \\
\hline Software & 1 & 29 \\
\hline Unspecified & 6 & $28,30-32,40,42$ \\
\hline
\end{tabular}

Table 3 Overview of types of virtual reality technologies used and associated studies. Note that some studies used more than one type of virtual reality technology.

\begin{tabular}{|l|l|l|}
\hline Virtual Reality Technology & $n$ & Studies \\
\hline CAVE & 1 & 28 \\
\hline Desktop & 2 & 27,41 \\
\hline HMD & 9 & $26,28-30,33,34,37-39$ \\
\hline Mobile & 2 & 29,40 \\
\hline Unspecified & 5 & $31,32,35,42,43$ \\
\hline
\end{tabular}

Table 4 Overview of class delivery formats.

\begin{tabular}{|l|l|l|l|}
\hline Item & $\begin{array}{l}\text { The study delivers a virtual reality } \\
\text { system via... }\end{array}$ & $n$ & Studies \\
\hline Virtual & $\begin{array}{l}\text { A three-dimensional virtual } \\
\text { environment representation of a } \\
\text { real-world learning environment. }\end{array}$ & 10 & $26,28,33-35,37-39,41,42$ \\
\hline Traditional & $\begin{array}{l}\text { A traditional, lecture-based, and in- } \\
\text { person learning environment which } \\
\text { is complemented by a virtual } \\
\text { reality system. }\end{array}$ & 6 & $27-29,35,40,43$ \\
\hline
\end{tabular}

This article is protected by copyright. All rights reserved. 
Table 5 Overview of study rationale or justification for using virtual reality in engineering education.

\begin{tabular}{|l|l|l|l|}
\hline Item & $\begin{array}{l}\text { The study justifies the use of } \\
\text { virtual reality by pointing to... }\end{array}$ & $n$ & Studies \\
\hline Distance Learning & $\begin{array}{l}\text { The benefits of distant learning } \\
\text { methods and/or virtual or remote } \\
\text { site access. }\end{array}$ & 3 & $34,35,41$ \\
\hline Immersive Learning & $\begin{array}{l}\text { The benefits of interactive and } \\
\text { immersive learning environments. }\end{array}$ & 9 & $26,29,32-35,38-40$ \\
\hline $\begin{array}{l}\text { Recent Development \& } \\
\text { Integration }\end{array}$ & $\begin{array}{l}\text { The recent advances in and/or } \\
\text { integration of virtual reality } \\
\text { technologies, specifically for use in } \\
\text { educational settings. }\end{array}$ & 10 & $27-33,37,42,43$ \\
\hline
\end{tabular}

Table 6 Overview of reported benefits to learning outcomes through use of virtual reality.

\begin{tabular}{|l|l|l|l|}
\hline Item & $\begin{array}{l}\text { The study describes learning } \\
\text { outcomes that aim to... }\end{array}$ & $n$ & Studies \\
\hline Skill-based Outcomes & $\begin{array}{l}\text { Improve students' examined and } \\
\text { graded academic scorings by using } \\
\text { virtual reality. }\end{array}$ & 5 & $28,29,35,40,43$ \\
\hline Cognitive Outcomes & $\begin{array}{l}\text { Improve students' longer-term } \\
\text { knowledge possession and overall } \\
\text { comprehension of academic } \\
\text { materials by using virtual reality. }\end{array}$ & 6 & $26,27,30,33,38,39$ \\
\hline Affective Outcomes & $\begin{array}{l}\text { Improve and facilitate students' } \\
\text { 'soft' skills (e.g., cooperation, } \\
\text { teamwork, etc.) acquisition and } \\
\text { development by using virtual } \\
\text { reality. }\end{array}$ & 4 & $30,31,41,42$ \\
\hline
\end{tabular}

This article is protected by copyright. All rights reserved. 
Table 7 Overview of metrics used in evaluation of virtual reality usage.

\begin{tabular}{|l|l|l|l|}
\hline Item & $\begin{array}{l}\text { The study analyses the virtual } \\
\text { reality system using metrics which } \\
\text { evaluate... }\end{array}$ & $n$ & Studies \\
\hline $\begin{array}{l}\text { Acceptability \& } \\
\text { Validity }\end{array}$ & $\begin{array}{l}\text { The level to which a system is } \\
\text { tolerated, allowed, and logically or } \\
\text { factually sound. }\end{array}$ & 2 & 37,38 \\
\hline Usability \& Usefulness & $\begin{array}{l}\text { The level to which a system is fit } \\
\text { or able to be used, and whether it } \\
\text { is perceived as actually useful. }\end{array}$ & 6 & $26,33,37,38,40,41$ \\
\hline Utility \& Effectiveness & $\begin{array}{l}\text { The level to which a system is } \\
\text { successfully produces the desired } \\
\text { result. }\end{array}$ & 8 & $27-30,35,38,42,43$ \\
\hline
\end{tabular}

This article is protected by copyright. All rights reserved. 


\section{University Library}

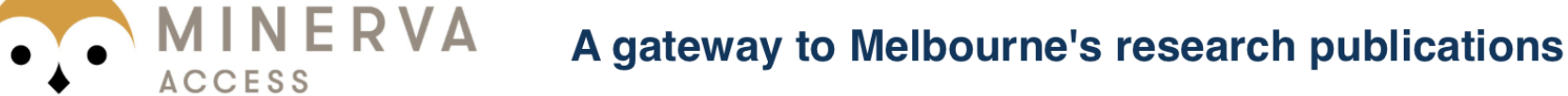

Minerva Access is the Institutional Repository of The University of Melbourne

\section{Author/s:}

di Lanzo, JA;Valentine, A;Sohel, F;Yapp, AYT;Muparadzi, KC;Abdelmalek, M

Title:

A review of the uses of virtual reality in engineering education

\section{Date:}

2020-04-22

Citation:

di Lanzo, J. A., Valentine, A., Sohel, F., Yapp, A. Y. T., Muparadzi, K. C. \& Abdelmalek, M. (2020). A review of the uses of virtual reality in engineering education. COMPUTER APPLICATIONS IN ENGINEERING EDUCATION, 28 (3), pp.748-763. https://doi.org/10.1002/ cae.22243.

Persistent Link:

http://hdl.handle.net/11343/286967 